\title{
BOSNIA AND HERZEGOVINA'S METALWORKING INDUSTRY COMPANIES BARRIERS TO EXPORT TO EU MARKET
}

\author{
UDC: $621.9(497.6): 339.564(4-672 \mathrm{EU})$ \\ Original Scientific Paper
Vesna K. SPASOJEVIC BRKIC ${ }^{1}$, Zorica A. VELJKOVIC ${ }^{2}$, Tamara GOLUBOVIC ${ }^{2}$, Snežana OMIĆ ${ }^{3}$, Aleksandar Đ. BRKIC ${ }^{4}$ \\ ${ }^{1}$ University of Belgrade, Faculty of Mechanical Engineering, Industrial Engineering Department, Kraljice Marije 16, \\ Belgrade, Serbia. \\ E-mail: vspasojevic@mas.bg.ac.rs \\ ${ }^{2}$ University of Belgrade, Faculty of Mechanical Engineering, Industrial Engineering Department, Kraljice Marije 16, \\ Belgrade, Serbia. \\ ${ }^{3}$ Ministry of Education, Science and Technological Development - Serbia, Nemanjina 22-26, Belgrade, Serbia. \\ ${ }^{4}$ University of Belgrade, Innovation Center, Faculty of Mechanical Engineering, Kraljice Marije 16, Belgrade, \\ Serbia.
}

Paper received: 22.09.2014.; Paper accepted: 28.10.2014.

\begin{abstract}
Export of products and services on EU market can bring great benefits, but also sets requirements to companies which are not easy to meet. Metal processing industry today is the main exporter in Bosnia and Herzegovina (BIH). However value of import significantly exceeds value of the export. Therefore, there is a need to increase export to EU market. The aim of this paper is an empirical examination of the export possibilities to EU market, conducted on a sample of 24 metal complex companies in BIH. Obtained results indicate that adequate marketing strategy is a minor influential factor for export to EU market. Also the research shows that a significant number of companies is not familiar with new approach directives, as well as with procedures for conformity assessment. Most of the surveyed companies have an opinion that there is not enough number of adequate laboratories and institutions for export assistance. Also, the lack of capital for export financing in the companies as export barrier is significant. This topic should be further researched, as it is very important for companies' growth and development in BIH.
\end{abstract}

Key words: export to EU market, formal requirements for export, barriers for export.

\section{INTRODUCTION}

European Union promotes market model that enables free exchange of people, goods and services. Export of manufactured goods to EU market brings great benefits, but also determines requirements to companies, which are not easy to fulfill (Kathuria, 2008). Companies today face a wide range of obstacles on their way to achieve possibility to export to EU market. Overcoming them brings great benefits to the companies, contributing also to the following:

- strengthening and better coordination of markets monitoring and control,

- strengthening legislative system and its application on the national level,

- securing coherence rules for work of notified bodies,
- secure that accreditation stays in public domain in order to avoid further multiplication in area of control of the products,

- further development of CE labeling (Belgrade Chamber of Commerce, 2006).

Bosnia and Herzegovina is actually on the 102 place according to competitiveness criteria of the West Balkan countries (Djordjevic et. al., 2011). Access to EU market offers to producers of Bosnia and Herzegovina (BIH) a unique opportunity to establish internationally competitive operations relying on a higher research and development and know-how component, together with using labor with higher skills. This is critical to the modernization of BIH's industrial base (Kaminski and $\mathrm{Ng}, 2010)$. Today, metalworking industry is a largest export sector in $\mathrm{BIH}$, with metals 
(aluminum and steel) as export products with the largest share. On the second place is automotive industry, with steady increase and significant developmental potential. Metal products also have important potential for further development, since in contemporary situation primary export is based on products with low added value.

Export of BIH metalworking industry in period from 2005 to 2010 had a maximum peak in 2008 , while in 2009 significant major decline occurred due to global recession. In 2010 export of BIH metalworking industry showed significant recovery. Independently of that the value of import all the time significantly exceeds value of export (Krčmar, 2013). Therefore there is an objective need to increase export from BIH to EU market.

The empirical findings of the Khara and Dogra (2009) on the sample of Indian companies suggest that the exporters face constraints classified into financial (availability and cost of finance), marketing (export marketing, export packaging and creativity), technological (related to access and quality management) and inputs (availability of skilled labor and raw materials). Hence, the goal of this paper is the empirical examination of export possibilities of BIH metalworking industry companies to EU countries.

\section{METHODS AND FINDINGS}

\section{BIH metalworking industry companies sample}

Survey of the companies was conducted via e-mail query to 400 companies from metalworking industry in BIH, using Google docs. Complete survey responses were obtained by 24 companies, 10 from Region of Sarajevo (SA) and 14 from the rest of Bosnia and Herzegovina $(\mathrm{rBIH})$, as shown in Table 1.

Table 1: Descriptive statistics - number of workers in surveyed companies in BIH

\begin{tabular}{|l|l|l|l|l|l|l|l|}
\hline & $\mathbf{N}$ & Mean & Median & Minimum & Maximum & St.Dev. & Coef.Var. (\%) \\
\hline BIH & 24 & 79.250 & 55.0 & 8 & 300 & 77.38 & 97.64 \\
\hline SA & 10 & 39.900 & 29.5 & 12 & 97 & 27.68 & 69.38 \\
\hline rBIH & 14 & 107.357 & 116.5 & 8 & 300 & 89.56 & 83.42 \\
\hline
\end{tabular}

Since coefficients of variations are larger than $30 \%$, indicating non homogeneous data, for further comparisons $\mathrm{U}^{*}$ test Mann-Whitney was used. The results show that there were no significant differences in company sizes between SA region and the rest of $\mathrm{BIH}$.

Most of the companies in both SA and BIH region are in metals and basic metals sub-sector (Figure 2), followed by machinery and equipment, while the smallest part belongs to electrical components, as in the whole population data according to
Kaminski and Ng (2010), confirming in that way the representativeness of the sample.

\section{BIH metalworking industry companies and export barriers}

Data regarding certified quality management system according to ISO 9001 were collected, since it is very important precondition for product export to EU market (Spasojevic Brkić et al., 2011, 2012). Data are presented in Figure 2.

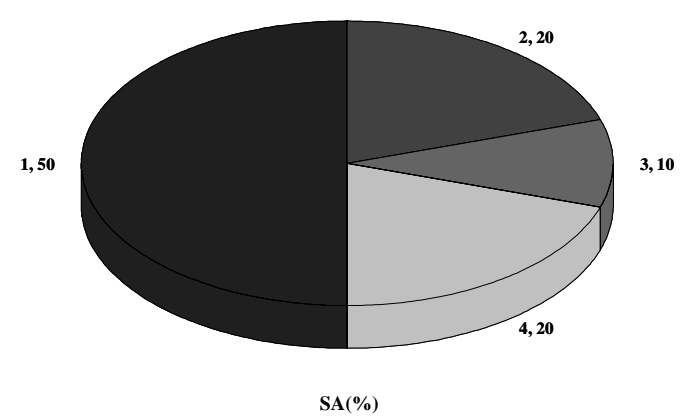

(b)

(a)

Figure 1: Metalworking industry sub-sectors for $r B I H(a)$ and $S A(b)$

Sub-sectors: 1 - Metals and basic metals, 2 - Machinery and equipment, 3 - Electrical equipment, 4 - Transport equipment 


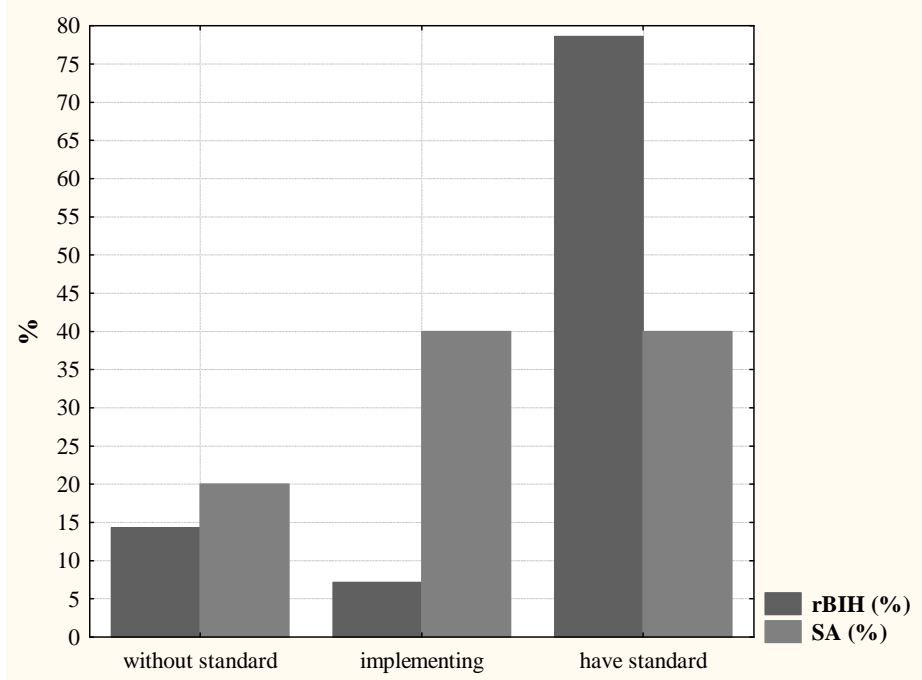

Figure 2: Data for ISO 9001 certificates in surveyed companies

Figure 2 shows that in SA region and in the rest of Bosnia and Herzegovina the largest part of surveyed companies have ISO 9001:2008 standard already implemented $(40 \%$ and $78.57 \%$, respectively). In SA region there is a large number of companies which are not even in the process of ISO 9001 standard implementation (20\%). Less than $20 \%$ of the companies are not interested in ISO 9001 standard implementation in both BIH regions.

Since it is also important to implement other ISO standards such as ISO 14001 and ISO 18001 (Karapetrovic and Spasojević-Brkić, 2014), data regarding these standards were also collected. Data show that in SA region $70 \%$ companies do not have these standards, while the rest of $30 \%$ are in process of their implementation. In $\mathrm{BIH}$ the observed standards are implemented in $50 \%$ of the surveyed companies, $7.14 \%$ are in process of implementation, while the rest of the companies have no particular interest for them $(42.86 \%)$.

Observation of financial status of the surveyed companies either in SA region or in $\mathrm{BIH}$, indicates the largest part of the companies are with "good" financial status, with one company having excellent financial status in SA. In BIH $42.86 \%$ companies are with "good" or "very good" financial status. This observation also indicates that financial status is not the only obstacle for exporting to EU market. Therefore further analysis is conducted in order to identify other factors that have influence on product or service export to EU market. These factors include product functionality $(\mathrm{PF})$, product appearance (PA), price of the product $(\mathrm{CP})$, necessary level of quality for certain type of product (NQ), adequate marketing (AM), product safety (PS) and technological level (TL).
Further analysis of influential factors for export to EU market indicates that there is no significant difference between regions, with adequate marketing (AM) as the least important factor (Figure 3). It is followed by product appearance characteristics (PA). As the most important factor, necessary level of quality for certain type of product (NQ) is found.

It should be noted that majority of the companies complains that the fulfillment of the formal requirements for export is extremely demanding job. For those reasons, the level of knowledge about directives necessary for export to EU market are examined in surveyed companies. The results (Figure 4) indicate that most of the companies are not informed about new directives approach.

In SA region $50 \%$ of the companies export products according to new directives, while in BIH this percentage amounts to $21.43 \%$. It should be noted that $50-57 \%$ companies don't know which kind of directives they are using for export to EU market.

In SA region $20 \%$ of the companies (i.e. 2 companies) are using at least one directive that belongs to new approach, while $30 \% \quad$ (3 companies) are using at least two directives simultaneously to export their products to foreign market. In BIH 3 companies (21.43\%) are using new approach directives and they differ from directives that are in use in SA region. Risk assessment guidelines for the general product safety directive in SA region is applied by 6 companies $(60 \%)$, while in $\mathrm{BIH}$ this percentage amounts to $21.43 \%$. 


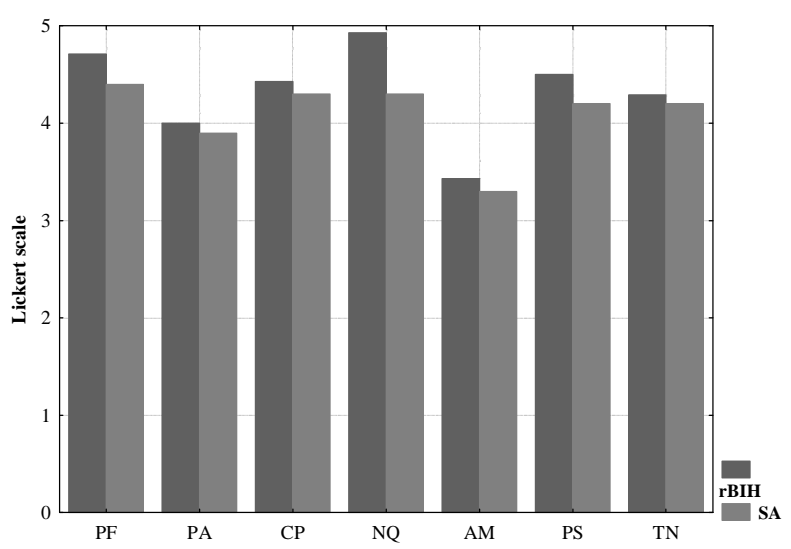

Figure 3. Comparison of influential factors for export to EU market

Legend: Product functionality (PF), Product appearance (PA), Cost price of the product (CP), Necessary level of quality for certain type of product (NQ), Adequate marketing (AM), Product safety (PS), Technological product level (TL)

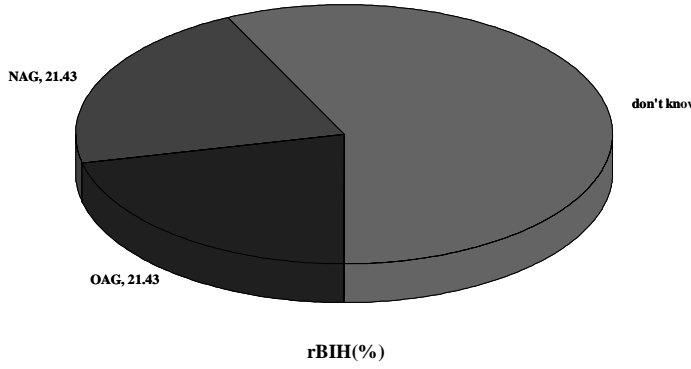

(a)

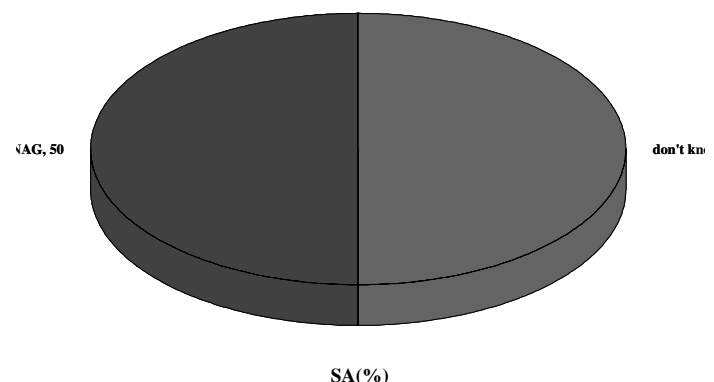

(b)

Figure 4: Application of guidelines for old and new approach in $\mathrm{rBIH}(\mathrm{a})$ and $\mathrm{SA}(\mathrm{b})$ Legend: New approach directives (NAG), Old approach directives $(O A G)$

Significant number of companies is not familiar with procedures for product conformity assessment. Most frequently, product conformity assessment is conducted by manufacturer or its authorized representative, for both SA region and $\mathrm{BIH}$. On the second place is notified body. Also, there is a large part of the companies in the sample that even do not know how product conformity assessment for their products should be conducted.

In the next step difficulties in meeting the formal requirements for export to EU market are analyzed (Figure 5).

Companies in SA region have slight difficulties in identification of the regulations, self-assessment of product conformity and in providing founds for requirements, comparing to the rest of BIH. From all of the surveyed companies only one of them in $\mathrm{BIH}$ had additional problems for fulfillment of the requirements for export to EU.

Examining opinions about the number of adequate laboratories that exist in BIH gave the following results. In SA region $40 \%$ of the companies are satisfied with their number, while in $\mathrm{BIH}$ this percentage is $28.57 \%$. Also in SA region there is a large number of the companies that didn't know how to answer this question (40\%). On the contrary in BIH more than half of the surveyed companies have an opinion that number of laboratories is insufficient.

On the question about sufficient number of institutions for export assistance in SA region answer is positive in $40 \%$ cases, while in $\mathrm{rBIH}$ this percent is $21.43 \%$. Furthermore opinion that number of institutions for export assistance is insufficient have $64.29 \%$ of surveyed companies in $\mathrm{BIH}$, while in SA that percentage is $30 \%$. The rest of the companies in SA region does not know the answer.

Final examination on the survey includes identification of factors that represent strongest obstacles for export to EU market (Figure 6), according to prior studies that have identified various internally controllable and uncontrollable factors as influencing on export performance (Brouthers et al., 2009). 


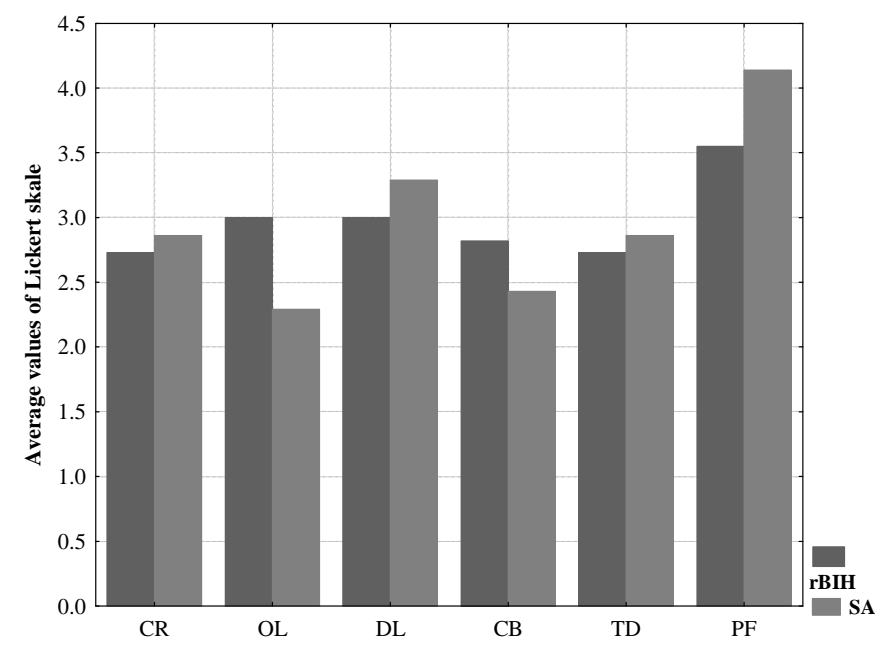

Figure 5: Difficulties in meeting the formal requirements for export to EU market

Legend: Identification of regulations which must be complied (CR), Acquisition of the regulations which must be complied (OR), Procedures for assessment of product conformity either as a self-assessment or by accredited laboratories (DL), Assessment of product conformity by competent body (CB), Assessment of product conformity - technical documentation forming (TD), Providing founds for fulfillment of the formal requests $(P F)$

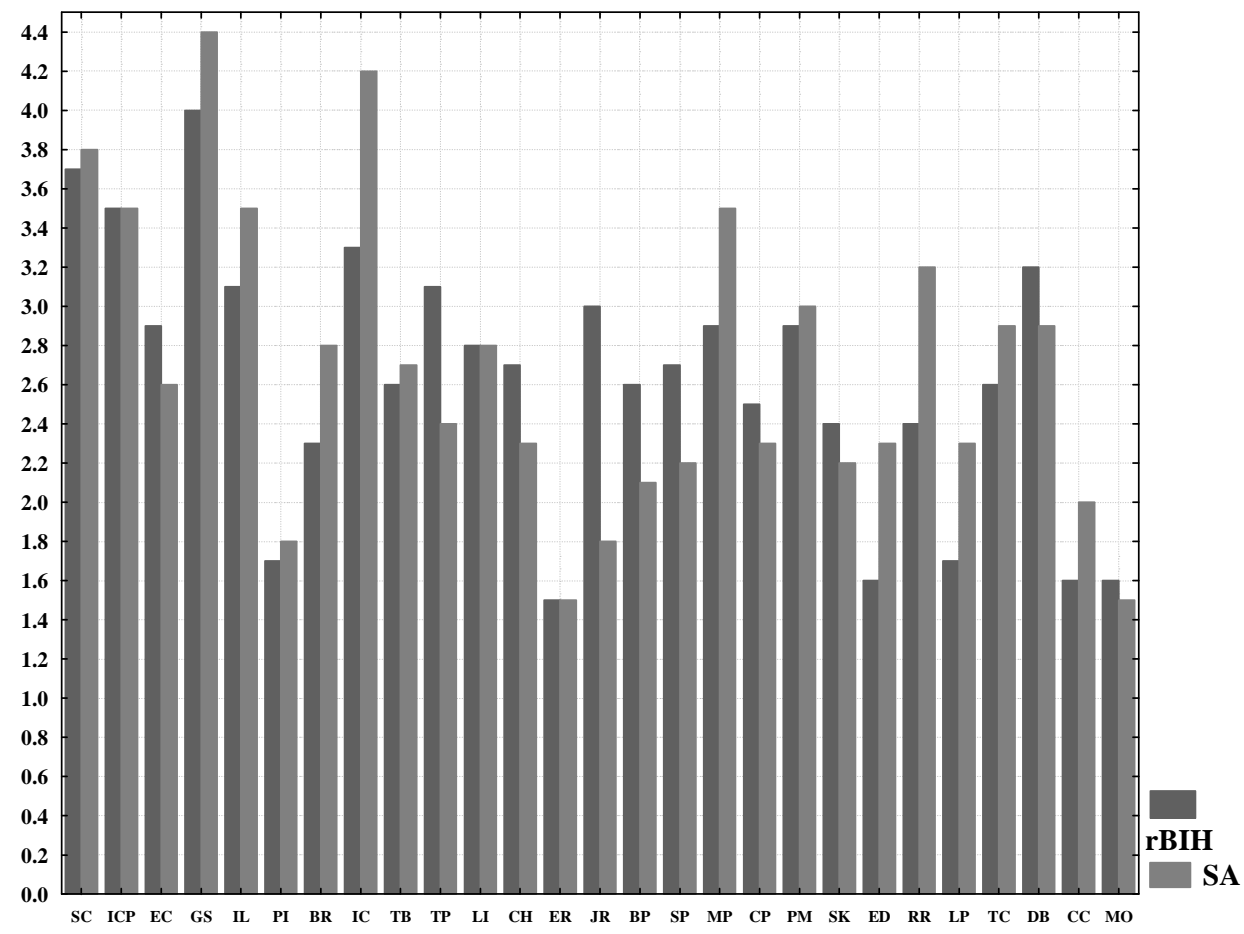

Figure 6: Strength of barriers for export to EU market

Legend: To strong competition in targeted EU country (SC), Inability to offer concurrent price (ICP), Worsening economic conditions in EU market (EC), Lack of government support and stimulus (GS), Lack of information for locating possible market and further analysis of EU market (IL), Political risk and instability in targeted EU country (PI), High business risks and costs in

targeted EU country (BR), Insufficient capital for export financing (IC), Tariff and non-tariff barriers (TB), Transportation problems (TP), Lack of information about regulation regarding export on EU market (LI), Different consumers attitudes and habits $(\mathrm{CH})$, Unfavorable exchange rate differences $(E R)$, Inadequate and untrained personal for work on jobs related to export $(J R)$, Lack of knowledge of foreign business practices $(B P)$, Problems with after sale service (SP), Impossibility of marketing and promotion in EU countries (MP), Customs problems (CP), Lack of information on potential EU market (PM), Storage problems for exported products $(S K)$, Export demands changes in products $(E D)$, Reliable representative in targeted country in $E U(R R)$,

Labeling and packing problems for export (LP), Testing and certifying demands for exported products (TC), Obstacles in domestic business environment (DB), Lack of knowledge of cultural characteristics and foreign languages (CC), Management and owner lack of interest for export (MO) 


\section{CONCLUSIONS}

According to the above analysis of the characteristics and possibilities for export to EU market of Bosnia and Herzegovina's metalworking industry covered by this survey, following conclusions can be drawn:

- Statistical testing by $\mathrm{U}^{*}$ test indicate that there are no statistically significant differences between sizes of surveyed companies in Sarajevo region and the rest of Bosnia and Herzegovina.

- In both examined areas the largest part of the companies belongs primary to the metals and basic metals sub-sector, followed by machinery and equipment sub-sector.

- In both examined areas most of the surveyed companies have implemented ISO 9001:2008 $(40 \%$ and $78.57 \%)$. Percentage of the companies in Sarajevo region without implemented ISO 9001:2008 is 20\%.

- In Sarajevo region 70\% of the companies don't have implemented management standards such as ISO 14001, ISO 18001 and similar, while the rest of the $30 \%$ are in the process of implementation. In the rest of Bosnia and Herzegovina $50 \%$ of the companies have implemented above mentioned standards, $7.14 \%$ is in implementation stage, while the rest of them, i.e. $42.86 \%$, has no intention to implement these standards.

- Regarding financial status of the companies in both examined areas, conclusion is that the most of them have medium financial potentials.

- Analysis of the influential factors on the placement of the products and services on EU market indicate that there are no significant differences between examined regions. Also this analysis points to adequate marketing as a minor influential factor.

- In Sarajevo region 50\% of companies' exports are conducted according to new approach directives, while in the rest of Bosnia and Herzegovina this percentage amounts to $21.43 \%$. In Sarajevo region half of the companies use at least one directive (some of them use two directives simultaneously). In the rest of Bosnia and Herzegovina 3 companies $(21.43 \%)$ use new approach directives. In Sarajevo region $60 \%$ of the companies use directives regarding general product safety, while they are used in $21.43 \%$ of the companies in the rest of Bosnia and Herzegovina.

- Significant number of the companies is not familiar with procedures for product conformity assessment. Most frequently product conformity assessment is conducted by manufacturer or its authorized representative, for both SA region and BIH. On the second place is notified body according to frequency of usage criteria. It is also important to notice that large part of the companies did not know the answer.

- Companies in Sarajevo region have slightly more problems to identify regulations, as well as to obtain financial support to fulfill the formal requirements for export to EU countries, than the rest of Bosnia and Herzegovina.

- The most of the companies in both examined areas $(60 \%$ and $57.14 \%)$ believe that consultant services should be used for formal requirements for export to EU market fulfilment.

- In Sarajevo region $40 \%$ of the companies have an opinion that there is a sufficient number of laboratories, while in the rest of Bosnia and Herzegovina this percent is $28.57 \%$.

- Opinions about sufficient number of competent bodies diametrically differ between Sarajevo region (where $70 \%$ of the companies think that there is a sufficient number of competent bodies) and rest of Bosnia and Herzegovina (where this percentage is $35.71 \%$, while $50 \%$ of them has an opinion that number of competent bodies is insufficient, while in Sarajevo region this percentage is only $10 \%$ ).

- In Sarajevo region prevails opinion that there is sufficient number of institutions for export to EU countries assistance (40\%), while in the rest of Bosnia and Herzegovina this percentage is only $21.43 \%$ of the surveyed companies. Consequently, in Bosnia and Herzegovina, without Sarajevo region there is an opinion that there are not enough institutions for export assistance $(64.29 \%)$. In Sarajevo region this percentage is $30 \%$.

- In Sarajevo region, $60 \%$ of surveyed companies have opinion that it is profitable to invest in obtaining formal requirements for export to EU countries. In the rest of Bosnia and Herzegovina majority of surveyed companies $(57.14 \%)$ don't know the answer to this question.

- In all surveyed companies lack of capital for export financing is significant, and that is a big limitation for export products to EU countries.

Regarding above conclusions it should be taken into account that samples were relatively small. Widening of the sample could in some instances lead to different conclusions and that is a proposal for further research. 
This topic should be further researched, as it is very important for companies' growth and development in BIH. In this country there are various problems with export to EU countries that can be solved without significant costs, such as poor knowledge in companies about this topic. According to results from this study potential to develop and increase export from BIH metalworking companies to EU counties certainly exists, and should be exploited in the future.

\section{ACKNOWLEDGMENTS}

This work is supported by a grant from MESTD TR 35017 project.

\section{REFERENCES}

Belgrade Chamber of Commerce (2006). Guidelines for dealing with the European Union (in Serbian), Belgrade, Serbia.

Brouthers, L. E., Nakos, G., Hadjimarcou, J., \& Brouthers, K. D. (2009). Key factors for successful export performance for small firms. Journal of International Marketing, 17(3), 21-38.

Đorđević, D., Ćoćkalo, D., \& Đurin, S. (2011). Serbian Enterprises and Global Competition Challenges. Journal of Engineering Management and Competitiveness (JEMC), 1(1/2), 27-31.
Kaminski, B., \& Ng, F. (2010). Bosnia and Herzegovina's surprising export performance: back to the past in a new veil but will it last? (Policy Research Working Paper 5187). Washington, DC: The World Bank.

Karapetrovic, S. \& Spasojević-Brkić, V. (2014), Usage of ISO 10000 Augmentative Standards in Serbia. Information technology, 1, 3, 18-ICIT: 21-23/4/14, UiTM-Sarawak.

Kathuria, S. (Ed.). (2008). Western Balkan integration and the EU: an agenda for trade and growth. Washington, DC: World Bank.

Khara, N., \& Dogra, B. (2009). Examination of export constraints affecting the export performance of the Indian sports goods industry. European Journal of International Management, 3(3), 382-392.

Krčmar, A. (2013). The external trade position and the export incentive measures of Republic of Srpska in relation to the practice of advanced economies. Acta Economica, 11(19), 281-299.

Spasojevic Brkić, V. K., Dondur, N., Curovic, D., \& Klarin, M. (2011). The relationship between effectiveness of quality management and total factor productivity. African Journal of Business Management, 5(22), 9200-9213.

Spasojević-Brkić, V., Đurđević, T., Omić, S., Klarin, M., \& Dondur, N. (2012). An empirical examination of quality tools impact on financial performances: Evidence from Serbia. Serbian Journal of Management, 7(1), 77-87. 